\title{
JUAN DE ÁVILA, UNA FIGURA QUE TRASCIENDE SU ÉPOCA
}

DOI: https://doi.org/10.52039/seminarios.v57i201-202.330

JUAN ESQUERDA BIFET ${ }^{1}$

\section{PRESENTACIÓN}

Remitirse a una figura de la historia eclesial, significa actualizar la realidad de gracia que hay en ella, como una herencia preciosa de familia que se quiere revivir. La «memoria» cristiana es siempre una actualización y no un simple recuerdo. Pero esta actualización supone, al mismo tiempo, discernir, armonizar y redimensionar lo recibido con las nuevas gracias que hoy comunica el mismo Espíritu Santo a su Iglesia.

La época del Maestro Juan de Ávila está amasada, como la nuestra, de luces y sombras. Es época de grandes «descubrimientos» geográficos y de nuevas aperturas en el campo intelectual y científico. Si se puede hablar de un «cambio de época», sería propiamente la del siglo XVI, donde ya se iniciaba una "globalización» incluso en el sentido geográfico y de intercambios culturales ${ }^{2}$.

Pero aquélla era también una época convulsionada por extremismos. Por una parte, la tendencia a confiar todo a la «gracia»; por otra parte, la tendencia a privilegiar el esfuerzo humano. La primera tendencia pedía mayor «libertad evangélica», mientras que la segunda intentaba valorar los medios y expresiones de la naturaleza. En este contexto, la Iglesia quería discernir y garantizar, en todas las tendencias, la precisión y la autenticidad.

En la sociedad de entonces, el acento en los descubrimientos de tipo más humano e incluso intelectual, se amalgamaba con tendencias «espirituales» o «fenomenológicas» no siempre auténticas. Se puede constatar también un cierto laxismo que daba lugar, como reacción, a un rigorismo difícil de precisar.

Es verdad que había también grandes y auténticos «carismas» (recibidos por personas verdaderamente libres), expresados en santidad y en renovación

1. Doctor en Teología. Gran conocedor de la obra de Juan de Ávila, a la que ha dedicado numerosos trabajos de investigación.

2. Es interesante esta observación del Papa Benedicto XVI: «La Spagna è stata, da sempre, un Paese 'originario' della fede; pensiamo che la rinascita del cattolicesimo nell'epoca moderna avviene sopratutto grazie alla Spagna; figure come sant'Ignazio di Loyola, santa Teresa d'Avila e san Giovanni d'Avila, sono figure che hanno realmente rinnovato il cattolicesimo, hanno formato la fisionomia del cattolicesimo moderno», cf. Entrevista a los periodistas durante el viaje hacia España, 6 noviembre 2010: L'Ossevatore Romano, 8-9 novembre 2010, 8. 
eclesial, mientras, al mismo tiempo, se acentuaba la evangelización «ad intra» y «ad extra». Pero tengo la impresión de que, si se hubiera seguido la línea equilibrada de San Juan de Ávila y la de otros santos de la época, no se hubiera producido posteriormente (dentro del catolicismo) el fenómeno jansenista, preñado de rigorismo, de miedos, de dudas y de desesperación, con secuelas que han durado siglos.

Lo que es auténtico en una época y en una cultura, tiene valor en otras y pasa a ser patrimonio común, salvando las perspectivas y los enriquecimientos posteriores. La armonía del corazón, la vida y la doctrina de San Juan de Ávila son un eco y casi una síntesis de toda la historia de la Iglesia, y a la vez son ya una herencia común decantada, que se transmite y acrecienta armónicamente.

Desde la perspectiva del inicio del tercer milenio, a mí me impresiona en Juan de Ávila su actitud relacional con Cristo (al estilo de Pablo), su vivencia y testimonio de la misericordia divina por medio de Cristo, y su armonía sapiencial y fecunda con apertura universalista cultural y espiritual. Es lo que quiero afrontar sucintamente en el presente estudio ${ }^{3}$.

\section{El AMOR DE CRISTO Y A CRISTO, CLAVE DE SU VIDA}

A Juan de Ávila no se le puede entender sin vivir, como él, en sintonía con los «sentimientos» de Cristo (cf. Flp 2, 5). Se pueden hacer muchos estudios técnicamente válidos sobre su figura, sobre su doctrina y sobre su ambiente histórico y cultural, pero para comprenderle hay que entrar en su vivencia de relación íntima de Cristo.

Este tema es de todos sabido, porque pertenece a la entraña del cristianismo, pero tal vez nuestra mentalidad actual, que está fuertemente condicionada por reflexiones de los siglos anteriores, tiende a apreciar menos los aspectos relacionales que eran tan sentidos por los santos, por autores espirituales y también por algunos teólogos de todas las épocas. Al respecto, es muy aleccionador este principio renovador sentado por Benedicto XVI en su primera encíclica Deus Ca-

3. La bibliografía avilista es hoy sumamente extensa (cf. las Obras Completas y estudios avilistas en la BAC). Sería muy útil poder disponer de la voluminosa "Positio» presentada para pedir su Doctorado: Urbis et Orbis Concessionis Tituli Doctoris Ecclesiae Universalis SANCTO IOANNI DE ÁVILA sacerdoti Dioecesano «Magíster» Nuncupatus (1499-1569). EI lector puede encontrar en ella prácticamente todo lo que se refiere al Santo Maestro, especialmente: Cronología y datos biográficos (cap. 1); Documentos Pontificios, de Cardenales y de Obispos (cap. 2); Predicador, fundador de Colegios y renovador (cap. 3); Escritor (cap. 4); Fuentes de su doctrina: Escritura, Tradición, Magisterio, Teología (cap. 5); Maestro (síntesis de su teología) (cap. 6); Maestro de espiritualidad cristiana (cap. 7) y sacerdotal (cap. 8); Influencia histórica y permanente (cap. 9); Actualidad para la Iglesia y el mundo de hoy (cap. 10); Doctrina eminente (cap. 11). Al final, se recoge toda la bibliografía hasta el momento, distribuida por ediciones, estudios biográficos, monografías, bibliografía reciente desde el año 2000 al 2008). Es muy útil la iconografía por su valor artístico y cultural. Termina con las «preces» suplicando el Doctorado. 
ritas est: «No se comienza a ser cristiano por una decisión ética o una gran idea, sino por el encuentro con un acontecimiento, con una Persona, que da un nuevo horizonte a la vida y, con ello, una orientación decisiva» (DCe 1) 4 .

Sobre San Juan de Ávila, el tema del amor de Cristo y a Cristo (con otros temas relacionados) ha sido ya estudiado con cierta amplitud. Nos limitamos a recordarlo sucintamente, haciendo referencia a algunos estudios sobre el particular. En sus escritos son continuas las referencias a Cristo amado profundamente, especialmente en intimidad con él ${ }^{5}$.

El Tratado sobre el Amor de Dios y el tema del Corazón de Jesús, evidencian esta intimidad profunda de Juan de Ávila con Cristo, que es la clave de toda su vida y actuación sacerdotal, como síntesis de su doctrina sobre el amor de Dios, la interioridad de Cristo (Esposo, crucificado, presente e inmolado en la Eucaristía), la cruz como expresión de este amor, la redención y la justificación por obra del amor de Cristo, la Iglesia amada por él, los «pobres» o las «almas» compradas y salvadas con su amor.

Especialmente en el Tratado sobre el Amor de Dios, tan apreciado por los especialistas en teología espiritual y tan citado por autores posteriores al Maestro, éste se muestra evidentemente como quien quiere compartir la misma suerte de Cristo, sus mismos amores. Ahí está la clave de su actitud relacional con Cristo, que matiza todos los otros temas:

¡Oh cruz, hazme lugar, y véame yo recibido mi cuerpo por ti y deja el de mi Señor. ¡Ensánchate, corona, para que pueda yo poner mi cabeza! ¡Dejad, clavos, esas manos inocentes y atravesad mi corazón y llagadlo de compasión y de amor! (n. 11).

El tema está íntimamente relacionado con el Corazón de Cristo y con la «locura» de la Cruz, al estilo de san Pablo: "¿Qué le falta a esa cruz para ser una espiritual ballesta, pues así hiere los corazones?... Esta santa cruz es el madero, y ese cuerpo extendido y brazos tan estirados, la cuerda. Y la abertura de ese costado es la nuez donde se pone la saeta de amor, por que de allí salga a herir el corazón... Cuando yo, mi buen Jesús, veo cómo de tu costado sale el hierro de la lanza, esa lanza es una saeta de amor que traspasa, y de tal manera hiere mi corazón, que no deja en él nada que no penetre... Vine aquí para cu-

4. Cita de nuevo la frase en la exhortación Verbum Domini, n. 11. Es un principio repetido continuamente por el Papa en sus intervenciones doctrinales, que tal vez no se tiene suficientemente en cuenta. Ver, por ejemplo, una afirmación de su homilía durante el inicio de su Pontificado (año 2005), citada en la exhortación sobre la Eucaristía (año 2007): «En la homilía durante la Celebración eucarística con la que he iniciado solemnemente mi ministerio en la Cátedra de Pedro, decía: « Nada hay más hermoso que haber sido alcanzados, sorprendidos, por el Evangelio, por Cristo. Nada más bello que conocerle y comunicar a los otros la amistad con él»... Verdaderamente, nada hay más hermoso que encontrar a Cristo y comunicarlo a los demás», cf. Exh. Apost. Sacramentum Caritatis, n. 84. Sin esta orientación básica (cristológica y relacional) no se entendería el magisterio de Benedicto XVI, como tampoco se valoraría adecuadamente a San Juan de Ávila. 
rarme, iy me has herido! Vine para que me enseñases a vivir, iy me haces loco! ¡Oh sapientísima locura: no me vea yo jamás sin ti... La cabeza tienes inclinada, para oírnos y darnos besos de paz... los brazos tendidos, para abrazarnos; las manos agujereadas, para darnos tus bienes; el costado abierto, para recibirnos en tus entrañas, los pies clavados, para esperarnos y para nunca te poder apartar de nosotros. Si se mira con atención, la cruz, los clavos, las heridas, y toda su figura es una invitación a amarle. Pero, sobre todo, es el amor interior me da voces que te ame y que nunca te olvide de mi corazón» (ibídem).

Esta intimidad con Cristo es el camino más adecuado para entrar en la intimidad trinitaria de Dios Amor. La mirada mutua de amor entre el Padre y el Hijo, se expresa personalmente en el Espíritu Santo que se nos comunica como salvación redentora: «¡Miraos siempre, Padre e Hijo, miraos siempre sin cesar, porque así se obre mi salud!» (ibídem, n. 12). «Este río tan hermoso es la gracia del Espíritu Santo, el cual procede del Padre y del Hijo, como de un principio; éste riega la gran ciudad, que es la Iglesia» (Sermón 45).

Esta misma dinámica relacional se evidencia también en el tema "Corazón» de Cristo: «Andad acá al Corazón de Señor» (Audi Filia, cap. 78). Porque Cristo «tendió sus brazos para ser crucificado, en señal que tenía su Corazón abierto con amor» (ibídem; cf. Carta 20/1). El Maestro invita a entrar en la intimidad con Cristo, quien «tiene el Corazón del Padre» (Sermón 34). Por esto nos guarda «a todos metidos en sus entrañas de caridad y amor» (Sermón 32).

Vivir en sintonía con los sentimientos de Cristo, es una gracia que hay que pedir: «Dadme, Señor, vuestro Corazón, y luego amaré lo que vos amáis, aborreceré lo que vos aborrecéis» (Sermón 28). Explicar la figura de Cristo sin estar enamorado de él, sería una contradicción: «El que no tiene Corazón de Cristo, este tal no es de Cristo» (ibídem) ${ }^{6}$.

El misterio de la Encarnación, que ha quedado fundamentalmente expuesto en el Tratado sobre el Amor de Dios, aflora en los escritos avilistas haciendo hincapié en la humanidad de Cristo. Por esto Cristo es alguien profundamente amado, cercano, que se quiere comunicar a todos. Este acento ayuda a valorar y vivir mejor (en sentido relacional y vivencial profundo) los demás temas, especialmente la Eucaristía y la Palabra de Dios.

El Maestro conoce y explica bien la base dogmática, al presentar una «humanidad levantada a ser supositada en Dios, y a ser personada en Él» (Sermón 46),

5. Cf. F.J. DíAz LoRITE, Experiencia del amor de Dios y plenitud del hombre en San Juan de Ávila, Madrid 2007; A. SEgoviA, «El amor de Dios en las cartas del P. Ávila», Maestro Ávila 1 (1946) 147-282.

6. Un estudio que sigue siendo actual: J.A. De AlDAMA, «El Bto. Juan de Ávila, precursor de Santa Margarita María de Alacoque en la devoción al Sagrado Corazón de Jesús», Maestro Ávila 1 (1946) 255-268. Ver también: M. BRUNSó, «El Beato Juan de Ávila y la encíclica 'Haurietis aquas'», Resurrexit 21 (1961) 309-311; J. Esquerda Bifet, «El Bto. Juan de Ávila, jalón imprescindible en la historia de la devoción al Corazón de Jesús», Surge 20 (1962) 227-233. 
«humanidad sublimada en alteza de persona de Dios» (Sermón 53). Pero el acento recae en la cercanía a nuestra realidad para salvarla: «Si el Señor no se quitara la vestidura de su grandeza, disimulándola, por lavar se quedaran los hombres, llenos de sus miserias y suciedades» (Sermón 74).

Este tema es muy apreciado en la mística española del siglo XVI y también por parte de algunos místicos anteriores, como San Bernardo, citado profusamente por el Maestro. Juan de Ávila lo explica con la imagen del «romero» o peregrino: «El Verbo, igual con el Padre, quiso hacer romería e pasar por el mundo peregrino. Toma ropa de paño grueso, el sayal de nuestra humanidad» (Sermón 18). La unión maravillosa entre "oro de divinidad y plata de humanidad», ha hecho posible que «saliese un ámbar, Cristo, que atrajese a sí las pajas, quiero decir, los pecadores, vanos como pajas, y los hiciese justos» (Sermón 22).

Este tema de la humanidad de Cristo no obnubila en nada su divinidad, sino que la hace más cercana. Es el Verbo Encarnado y Redentor. Así podemos «ver a Dios abajado y humanado... pues este modo de remediarnos por su humildad y bajeza está mejor a gloria de Dios y al bien de los hombres... su humanidad y humildad fueron testimonio de su bondad» (Audi Filia, cap. 41). Éste es el modo de actuar de Dios Amor: "Así el camino usado de comunicar Dios su divinidad con las ánimas es por medio de su sacra humanidad» (ibídem, cap. 68).

La vida espiritual cristiana no pasaría de ser una experiencia fenomenológica personalista o una abstracción, si no se inspirara en la fuente primera que es Dios Amor: «De esta misma fuente sale la manera que se ha de tener en amar la santa Humanidad de Cristo nuestro Redentor, porque, como nuestro amor ha de ser holgarnos de la gloria que tiene Dios, de aquí ha de nascer holgarnos que aquella ánima santísima de Cristo esté rellena de gloria como está, alabando y engrandeciendo a la Divinidad» (Carta 222).

El camino de la oración cristiana no es principalmente de explicaciones teóricas ni de simples metodologías (por válidas y útiles que puedan ser), sino una actitud sencilla de sintonía con Alguien presente que nos lleva en su corazón. La oración es una actitud relacional, a modo de movimiento del corazón: "Cuando nosotros oramos, Él (Cristo) ora en nosotros» (Audi Filia, cap. 84; cf. San Agustín, Enarr. in Ps., 85, 1). Es «una sosegada atención para aprender de su maestro» (Audi Filia, cap. 75), una «secreta y amigable habla con Él» (ibídem, cap. 6)7.

Estos principios que acabamos de resumir, no son sólo para personas privilegiadas, sino que Juan de Ávila los explicaba, más sencillamente, también en sus sermones: «Graciosa y muy agradable oración haréis si, dondequiera que

7. Cf. F. Borraz Girona, De theologia orationis iuxta doctrinam Sancti Johannis de Avila (Roma, Univ. Santo Tomás, 1975; Burgos 1976; Tesis Doctoral); E. M. ${ }^{a}$ Díaz RAmíreZ, Vino nuevo. Orar con San Juan de Ávila, Barcelona 1984; J. EsqUERDA BIFET, «La oración contemplativa en relación a la devoción mariana según el Maestro Juan de Ávila», Anthologica Annua 24-25 (19771978) 499-550; J. L. MoReno Martínez, San Juan de Avila, Maestro de oración, Burgos 2002; J. SANCHIS, «Doctrina del Bto. Juan de Ávila sobre la oración», Verdad y Vida 5 (1947) 5-64. 
os hallareis, alzareis vuestros corazones a Dios y lo tuviereis presente en vuestra memoria. ¿Quién os estorbará que no podáis hacer esto?... Comunicaos con Él, recogeos un poco a solas con Él en vuestro rinconcillo, si queréis sanar de vuestros males» (Sermón 10).

Es una actitud parecida a la explicada por Teresa de Ávila («estando... con quien sabemos que nos ama») y aconsejada sencillamente por el Santo Cura de Ars («alegres con su presencia»). Dice el Maestro Ávila: «Quédase allí solo, descansando. Por esto quien quisiere negociar con Él, vaya, que allí lo hallará solo, y el negocio que Él más quiere es que vais a regocijaros con Él» (Sermón 11). Es como la «sencilla mirada del corazón» (Teresa de Lisieux) o como dice el Maestro: «Perseveremos en mirar a Dios» (Sermón 129).

Su docencia era vivencial y testimoniada. Cuando exponía los temas evangélicos, especialmente durante la homilía, toda la explicación giraba en torno a la persona de Jesús que ahora está presente y habla al corazón. Es que el evangelio sigue acontecimiento en la vida de cada persona y en toda la sociedad.

La Palabra de Dios es anunciada para escucharla en el corazón y vivirla, ahora concretada en el mismo Jesús: «Aunque a toda la Escritura de Dios hayáis de inclinar vuestra oreja con igual crédito de fe, porque toda ella es palabra de una misma suma Verdad, mas debéis tener particular respecto de os aprovechar de las benditas palabras que en la tierra habló el verdadero Dios hecho carne» (Audi Filia, cap. 45; comenta Mt 17, 5: «Este es mi muy amado Hijo»). Al leer el evangelio, aquello que Cristo dijo e hizo acontece de nuevo, especialmente en relación con la Eucaristía: «Aquí lo hallarás haciendo otro tanto» (Sermón 41).

De ahí el significado e importancia de la predicación. Los predicadores son «espuertas de la semilla y palabra de Dios». Y añade: «No tengáis en poco la semilla si la espuerta es vil» (Sermón 28). De esta predicación surge la verdadera renovación de la Iglesia: «Los que predican reformación de Iglesia, por predicación e imitación de Cristo crucificado lo han de hacer y pretender» (Plática $4^{\mathrm{a}}$; pone el ejemplo de Santo Domingo y San Francisco). Por esto puede afirmar: "¿Sabéis cuál fue la causa de vida eclesial? Haber predicadores, encendidos con fuego de amor celestial, que encendían los corazones de los oyentes al fervoroso amor de Jesucristo nuestro Señor» (Sermón 55$)^{8}$.

El Año litúrgico es un itinerario de encuentro con Cristo, que hace presente o actualiza sus momentos salvíficos. Los sermones avilistas tenían lugar en los principales momentos de la vida litúrgica (Adviento, Navidad, Cuaresma, Pas-

8. Algunos estudios más recientes sobre la predicación en San Juan de Ávila: J. J. GAllego Palomero, El ministerio de la predicación y San Juan de Avila, en AA.VV., El Maestro Ávila. Actas del Congreso Internacional (Madrid, 27-30 noviembre 2000), Madrid 2002, 799849; S. LóPez SANTIDRIÁN, Juan de Ávila predicador de Cristo, Madrid 2000. Ver contenidos de la predicación y bibliografía en L. Sala Balust-F. Martín HeRnández, Santo Maestro Juan de Ávila, Madrid 1970, 274-289 (El Maestro Ávila, predicador). Ver esa dimensión relacional y vivencial de la Palabra de Dios en la exhortación Verbum Domini, nn. 51-59. 
cua, Pentecostés, Corpus Christi, fiestas marianas, etc.). El Maestro invitada a vivir en sintonía con el Misterio de Cristo: «Habéis de saber, hermano, que, aunque las fiestas de Dios se pasaron cuanto a la historia, pero no se pasaron cuanto a la virtud... Siempre dura la virtud de la pasión hasta que el mundo se acabe» (Sermón 27) ${ }^{9}$.

La presencia de Cristo, nacido de María, hay que detectarla en «las almas», es decir, en todos los redimidos, especialmente en los más pobres. La perspectiva relacional (de intimidad con Cristo) lleva necesariamente al encuentro con Cristo en los inmensos campos de caridad. Sólo a la luz de su amor apasionado por Cristo se explica la dedicación continua a las diversas necesidades espirituales, educativas, materiales.

El celo de almas (con derivaciones hacia todos los campos de caridad) es un contagio o trasunto de los amores de Cristo: «En cruz murió el Señor por las ánimas; hacienda, honra, fama y a su propia Madre dejó por cumplir con ellas» (Sermón 81). «Porque el fin de su encarnación, y de su vida, y de sus trabajos y muerte, es el bien de las ánimas» (Sermón 36). Por esto, el Señor «meterse ha por lanzas por amor de las ánimas» (Sermón 76). «Si de veras nos quemase las entrañas el celo de la casa de Dios... ¡Cómo tendrá paciencia en ver las esposas de Cristo enajenadas de Él y atadas con nudo de amor tan falso!» (Carta 208).

El universalismo de la misión realizada por San Juan de Ávila tiene dimensión geográfica, pero también cultural y sociológica: «¡Quién pudiese tener mil millones de lenguas para pregonar por todas partes quién es Jesucristo!» (Carta 207). Los más pobres (pecadores, enfermos, pobres materiales) conmovían su corazón, como trasunto del Corazón de Cristo. Por esto se lamenta de que «tenga Cristo tan pocos servidores en negocio de pobres» (Carta 204).

Este campo preferencial de los «pobres» lo recalca en tiempo de Navidad, cuando Cristo nace pobre para hacerse encontradizo: "Y mire que lo trate y cure bien, que es Hijo de alto Rey; Hijo es de Virgen y en virginales corazones reposa de buena gana... Y porque tiene muchos parientes pobres, y quien a Él quiere, también ha de querer a ellos, tienda vuestra merced la mano para les dar, porque son hermanos del Criador» (Carta 67).

Su amor a María y a la Iglesia están en esta perspectiva de Cristo que llega a nosotros por medio de signos cercanos a nuestra realidad. María «dio al Verbo de Dios el ser hombre, engendrándole de su purísima sangre, siendo hecha verdadera y natural Madre de Él» (Tratado sobre el sacerdocio, n. 2). «Conocer»a María equivale a conocer a Cristo como Redentor, «conocer nuestro Redentor y nuestro remedio» (Sermón 6).

9. Cf. J. EsqueRdA BifET, El año litúrgico en los sermones de san Juan de Ávila, AA.VV., Fovenda sacra liturgia. Miscelánea en honor del Dr. Pere Tarrés, Barcelona 2000, 427-442. Ver este mismo tono vivencial de «encuentro con Cristo» en la exhortación Verbum Domini, nn. 52, 72-74, 77. 
La Madre de Jesús invita a vivir la Eucaristía: «Venid y comed del pan que yo concebí en mis entrañas, y del pan que yo parí (Sermón 12). Allí está «la guirnalda de la humanidad que le dio su santísima Madre» (Sermón 36). Es el «pan de la Virgen» (Sermón 39). «Ella es la que nos lo guisó, y por ser ella la guisandera se le pega más sabor al manjar» (Sermón 41). «Ella fue... la que nos amasó este pan» (Sermón 46) ${ }^{10}$.

El Misterio de Cristo se actualiza en el misterio de la Iglesia profundamente amada de Cristo. Este misterio se capta como «desposorio... del Verbo hecho hombre con su Iglesia, que somos nosotros... en el día de Viernes Santo casó por palabras de presente con esta su Iglesia... porque entonces le fue sacada de su costado, estando Él durmiendo el sueño de muerte» (Audi Filia, cap. 69).

El camino de la santidad cristiana es una respuesta al amor de Cristo Esposo a su Iglesia esposa, llamada a vivir el estilo de vida de Cristo: «La Iglesia cristiana tanto más lo conoce por su verdadero Esposo y Ungido, cuanto más pobreza y desprecio y trabajos trae» (Carta 127). Comentando el texto paulino sobre el amor de Cristo a su Iglesia para santificarla (Ef 5, 25-26), dice: «Si la santifica, lava y limpia, y aun con su propia sangre, que es la que da virtud a los sacramentos, para limpiar las ánimas por la gracia que da, ¿cómo puede quedar injusta o sucia la que con tan eficacísima cosa es limpiada y lavada?» (Audi Filia, cap. 88).

El amor apasionado del Maestro Ávila por Cristo es un trasunto del amor del apóstol Pablo: «Muerto estaba el Apóstol para la gloria y honra del mundo... Muerto estaba el Apóstol al mundo para sentir sus afrentas, persecuciones y adversidades... Vivo estaba para sentir las afrentas de Jesucristo y las ofensas que contra él se hacían... Vivo estaba el Apóstol para Dios, pues con tanto cuidado entiende en las cosas que tocan a su servicio» (Comentario a Gálatas, n. 27) ${ }^{11}$.

Así el Maestro Ávila podía vivir y anunciar a Cristo desde la realidad humana, personal y sociocultural, donde está presente Cristo esperando al creyente y al apóstol. Ahí enraíza el tema de la misericordia que veremos a continuación.

\section{TESTIGO DE LA MISERICORDIA DIVINA EN UNA ÉPOCA GRANDIOSA Y CONVULSIONADA}

En la enseñanza y vivencia de San Juan de Ávila, la experiencia de intimidad con Cristo se apoya en la bondad y misericordia de Dios humanado. Sin esta perspectiva de misericordia, no se entendería el misterio de Cristo presente en

10. Sobre su doctrina mariana: J. ESQUERDA BIFET, «La doctrina mariológica del Maestro san Juan de Ávila», Marianum 62 (2001) 91-114; D. FERNÁNDEZ, «Culto y devoción popular a María en la obra de San Juan de Ávila», Ephemerides Mariologicae 31 (1981) 79-99; A.P. GonZÁlez Gutí́RREZ, «La actuación de María en la Iglesia de Cristo según San Juan de Ávila», Scripta de Maria 9 (Pamplona, 1987) 109-147; A. MoLINA, «Presencia de María en el epistolario del Santo Maestro Juan de Ávila», Estudios Marianos 36 (1972) 281-304.

11. Cf. B. Jiménez Duque, El Maestro Juan de Ávila, Madrid 1988, cap. XIV; R. García VILLOSLADA, «El paulinismo de Juan de Ávila», Gregorianum 51 (1970) 615-647. 
la Iglesia. Cristo es la misericordia personificada. La Iglesia es expresión transparente y eficaz («sacramento») de esta misma misericordia.

Para entender mejor el acento del Maestro Ávila en la misericordia, hay que considerar el ambiente histórico y eclesial de la época. La tensión surgía de subrayar unilateralmente o la gracia o el esfuerzo humano. Ello produjo una ruptura en la Iglesia, separándose de ella los llamados «reformadores» o «evangélicos» (protestantes). Dentro de la Iglesia, la tensión continuó, también en los debates teológicos. Posteriormente (desde el siglo XVII) el jansenismo, tendencia rigorista, influirá en grandes sectores de la Iglesia hasta bien entrado el XIX.

En Juan de Ávila (y en otros santos de la época) encontramos un gran equilibrio y armonía entre gracia y cooperación humana. Tal equilibrio no nace de discusiones o exposiciones teóricas, sino de un corazón unificado que ha experimentado en sí mismo (en la propia realidad limitada) la misericordia de Dios.

La corriente dominante de la época podría calificarse de humanismo renacentista, pero muy polifacético por el hecho de incluir aspectos de diversas corrientes o tendencias: biblistas, nominalistas, reformistas, críticas (erasmismo), espiritualistas (alumbradismo), quietistas, etc. ${ }^{12}$

En medio de estas tensiones, afloraba una corriente renovadora, humanista y espiritual a la vez. En esta parte más positiva se colocan, junto al Maestro Ávila, los santos y grandes autores espirituales españoles de la época: Tomás de Villanueva, Juan de Ribera, Ignacio de Loyola, Juan de Dios, Pedro de Alcántara, Teresa de Ávila, Juan de la Cruz, Francisco de Borja, Luis de Granada... Son ellos quienes supieron afrontar constructivamente los problemas prácticos o pastorales que surgían, derivados a veces del pensamiento humanista, filosófico y teológico. La renovación de las Órdenes religiosas y la creación de los Seminarios programados por Trento, surgieron en este ambiente. No hay que olvidar la institución de numerosos centros culturales en España, entre lo que cabe destacar unas 30 universidades hacia el final del siglo XVI.

Como es sabido, a San Juan de Ávila le tocó en suerte colaborar en la creación de algunos Seminarios, Colegios y Universidades, dentro de este ambiente histórico y cultural, antes y después de Trento (al que él aportó su propia experiencia transcrita en los célebres «Memoriales»). Al Maestro Ávila le preocupaba el bien integral de toda persona, como miembro de la sociedad. Organizó misiones populares, catequesis, centros educativos y caritativos. Instó a todos a compartir los bienes con los pobres. Propuso al concilio de Trento la creación de una especie de tribunal internacional para evitar las guerras y las injusticias entre los pueblos (cf. Memorial para el concilio de Trento I, n. 63).

12. Cf. F. MÁrquez VilLanUeVA, «Vida y escritos de San Juan de Ávila a la luz de sus tiempos», en AA.VV., El Maestro Ávila. Actas del Congreso Internacional (Madrid, 27-30 noviembre 2000), Madrid 2002, 77-98. Resumen espiritual y cultural de la época: M. ANDRÉs MARTín, Historia de la mística de la edad de oro en España y América, Madrid 1994. 
En este contexto, su enseñanza, especialmente por medio de la predicación y las numerosas cartas, es una llamada continua a la perfección, a la conversión y al perdón. Detecta las llagas y ofrece el ungüento de la misericordia divina. Insta a un cambio profundo de personas y estructuras. Las lacras de aquella época («tiempos tan faltos de temor de Dios y de amor de virtud») tienen que reconocerse ante la oferta del perdón de Dios. La gracia, que es vida y acción del Espíritu Santo, hace posible que el ser humano recupere su verdadera libertad. El Maestro predica la misericordia y forma apóstoles de la misericordia ${ }^{13}$.

El contenido de sus sermones (que reflejan su propia actuación pastoral y la de sus discípulos) gira continuamente en torno al amor de Dios, que es exigente y que hace posible el perdón y la recuperación. Dios es «padre amoroso y perdonador» (Audi Filia, cap. 41) y su amor es tierno como de madre (cf. ibídem, cap. 80; Sermón 77). En Cristo, el Verbo Encarnado, Dios tiene «ternura de corazón... entrañas de misericordia», porque «Dios es Amor» (Sermón 76).

En las cartas de dirección espiritual y en los sermones, ayuda a vivir un equilibrio entre el reconocimiento del propio pecado y la confianza en la misericordia divina: «Lo que escarbáis en vuestra miseria, escarbadlo en su misericordia» (Carta 139). «Vete con Él, que más puede su misericordia y los trabajos que Él pasó por ti para agradar a Dios Padre, que tus culpas para desagradarlo» (Sermón 19). «No hay momento en que la misericordia y largueza del Señor no esté lloviendo en ti nuevas mercedes» (Sermón 42).

Este perdón tan generoso de Dios, pide y hace posible la propia penitencia, también celebrando el sacramento del perdón: «Porque el que es parte y juez nos perdona y nos absuelve, mediante nuestra penitencia, y sus ministros y sacramentos» (Audi Filia, cap. 18). Dios obra «según su costumbre. Y de aquí viene que, en lugar de airado juez, nos sea Dios piadoso Padre» (ibídem, cap. 20). «Toma Dios por honra de su nombre el perdonar, y perdonar mucho» (ibídem, cap. 21; comenta el salmo 50).

En momentos de duda y angustia sobre la propia realidad pecadora, hay que tener presente la misericordia divina, porque, por grandes que sean nuestros pecados, «clama más alto sin comparación la sangre de Cristo, pidiendo perdón a las orejas de la misericordia divina» (Audi Filia, cap. 85). La pasión que sufrió el Señor hace que, «mirándolo el Padre tan afligido y sin culpa, mirase a los culpados con ojos de misericordia» (ibídem, cap. 87). Por la Encarnación del Verbo,

13. Pablo VI, en el discurso durante la audiencia después de la canonización, resume el ambiente de la época: «La figura de San Juan de Ávila surge ahora casi podríamos decir con una finalidad profética, para marcaros una pauta. Él supo captar los problemas de vuestra Patria, que en aquel entonces abría su seno al Mundo Nuevo recientemente descubierto; supo asimilar con espíritu de Iglesia las nuevas corrientes humanistas; supo reaccionar con visión certera ante los problemas del sacerdote, sintiendo la necesidad de purificarse, de reformarse para reemprender con nuevas energías el camino», cf. PABLO VI, Discurso 1 de junio de 1970: Insegnamenti VIII/1970, 570. 
conocemos que «este que viene es amigo de misericordia» (Sermón 2). Hasta el punto de que quienes se condenan es «porque no confían de la misericordia de Dios» (Sermón 19).

Es conmovedor el modo cómo San Juan de Ávila invita a acudir a la misericordia divina, como acabamos de ver, con expresiones que seguramente leyó el Santo Cura de $\operatorname{Ars}^{14}$.

Es también una nota peculiar de la doctrina avilista, el tema de la «mirada» de Dios Amor: nos mira (también cuando somos pecadores y queremos arrepentirnos) por medio del rostro de su Hijo crucificado: «Esta faz es mirada del eterno Padre» (Carta 59), quien nos mira «por los agujeros de sus llagas» (Carta 139). Dios nos mira perdonándonos: «Así que el principio y primero mirar de los ojos de Dios no es contra el hombre que Él crió, mas contra el pecado que nosotros hicimos» (Audi Filia, cap. 86). Dios «mira en la faz de su Cristo» (Audi Filia, cap. 87). «Porque, así como el mirar de Dios a nosotros nos causa todos los bienes, así el mirar Dios a su Cristo, trae a nos la vista de Dios... El ser amado Cristo, es razón de ser recibidos en gracia nosotros» (ibídem).

La mirada de Dios es, pues, de amor misericordioso, expresado en la mirada a su Hijo y a nosotros en él: «Porque después que Cristo murió por nosotros, ya nos mira Dios con otros ojos, míranos con el amor que a su Hijo bendito» (Sermón 32). Dios nos mira con «amorosos ojos» porque estamos «incorporados» en su Hijo Jesucristo (Sermón 34). «Es levantado el hombre a ser miembro vivo de Jesucristo nuestro Señor y a ser llamado por nombre de Él; y por ser cosa de Cristo, es mirado del Padre con amorosos ojos y tiene cuidado como de cosa tan conjunta a su Hijo» (ibídem). Ya podemos decir al Padre: «Míranos por Él, pues nos redimiste por Él» (Sermón 55). La mirada amorosa de Dios nos invita a mirarlo con confianza filial: «Mirad, pues, a Cristo, porque os mire Cristo a vos» (Audi Filia, cap. 112) ${ }^{15}$.

14. En la biblioteca del Santo Cura de Ars se conservan las obras del Maestro Ávila (traducción francesa). Así lo afirma la revista «Annales d'Ars», n.42 (jan.-fev. 1963), reproduciendo una carta del Maestro Ávila (con ideas parecidas a las del Santo Cura). Ver textos de Vianney sobre la misericordia divina, citados por Benedicto XVI en la Carta para la apertura del año sacerdotal (16 junio 2009): (Ponía en boca de Jesús) «Encargaré a mis ministros que anuncien a los pecadores que estoy siempre dispuesto a recibirlos, que mi misericordia es infinita». «El buen Dios lo sabe todo. Antes incluso de que se lo confeséis, sabe ya que pecaréis nuevamente y sin embargo os perdona. ¡Qué grande es el amor de nuestro Dios que le lleva incluso a olvidar voluntariamente el futuro, con tal de perdonarnos!». Las referencias bibliográficas están en las notas 24 y 25 de la Carta, donde cita a: Le curé d'Ars. Sa pensée - Son coeur. Présentés par l'Abbé Bernard Nodet, éd. Xavier Mappus, Foi Vivante, 1966, 130-131. Cf. edición española: B. Nodet, Juan-María B. Vianney, Cura de Ars. Su pensamiento y su corazón, Barcelona 1994. También hay ciertos parecidos en doctrina sobre la oración, como hemos visto en apartado anterior.

15. En la primera edición del Audi Filia se añadía: «Vos veréis a vos en Él y Él verá a Sí en vos» (Audi Filia, cap. 112). En la edición definitiva, el Maestro la matizó por exigencia de los censores, y puso: «De gracia, que no de deuda, se vistió nuestra fealdad, y de gracia, sin deuda, nos vistió de esta hermosura» (ibídem). 
La misericordia divina la experimentamos de modo especial en el amor materno de María hacia todos los redimidos. Ella es «Madre de misericordia» o «enfermera del hospital de la misericordia de Dios» (Sermón 60). Por esto, el Maestro invita a acudir a ella con confianza filial: «Os será muy verdadera Madre en todas vuestras necesidades» (Audi Filia, cap. 59).

Esta experiencia de la misericordia divina unifica el corazón y siembra la paz y la armonía en la sociedad y en la Iglesia. La actuación pastoral del Maestro Ávila en sus sermones y en las cartas de dirección espiritual, era, al mismo tiempo, exigente y comprensiva: «Sus palabras, aunque fuesen de reprensión, iban envueltas en amor, caridad y celo del aprovechamiento de las almas, y así le oían con notable afecto» ${ }^{16}$.

Las cartas a sus discípulos, que eran también confesores o directores espirituales, tienen este mismo tono. Hay que presentar ideales de perfección, alentando con actitud paterna y amigable. De este modo, la persona dirigida se siente escuchada y motivada. El director o confesor es «guía y padre» (Reglas de espíritu, II, n. 9). A su dirigido el P. Luis de Granada, le da unas líneas de actuación hacia sus propios dirigidos: «El espíritu de padre para con sus hijos», con un «cuidadoso y fuerte amor que Él (Dios) pone en un hijo suyo con otros hombres... aunque sea quitándose el padre el bocado de la boca, y aun dejar de estar entre los coros celestiales para descender a dar sopitas al niño». Por esto, «es menester estar siempre templado, porque no halle el niño alguna respuesta menos amorosa... a quien quisiere ser padre, conviénele un corazón tierno... para haber compasión de los hijos» (Carta 1).

\section{ARMONÍA DE LA REVELACIÓN Y DE LA FE EN UNA SÍNTESIS SAPIENCIAL Y FECUNDA}

Leyendo los escritos de San Juan de Ávila, el lector queda sumergido armónicamente en toda la historia de la Iglesia, en el sentido de encontrar los contenidos de la revelación (Escritura y Tradición), vividos, celebrados, enseñados y estudiados en la comunidad eclesial. Es una armonía maravillosa entre todos los aspectos, respetando la peculiaridad de cada uno. Se puede analizar la doctrina avilista en sus contenidos escriturísticos, patrísticos, magisteriales, litúrgicos, siempre insertados en una realidad cultural y sociológica. Se aprecia fácilmente la armonía entre fe y razón, gracia y naturaleza (humanismo), exigencia y posibilidad, urgencia y comprensión.

Quien entra en sintonía con esta armonía polifacética, se contagia del amor a la Iglesia, también con el deseo humilde y audaz de colaborar en su renovación. Es una armonía que no aprisiona, sino que abre a un futuro siempre prometedor. Por esto, la figura de San Juan de Ávila ha tenido y sigue teniendo un influjo uni- 
versalista, que respeta carismas o gracias diferentes. Ahí está el secreto de haber sido tan apreciado por todos los santos y todas las Órdenes religiosas de su tiempo. Su enseñanza llega a todas las vocaciones específicas o estados de vida, sin oponerlas ni superponerlas: laicado, vida consagrada, sacerdocio ministerial.

A partir de esta armonía, se puede deducir su influjo permanente, capaz de insertarse en toda época y en cada cultura, sin condicionar a nadie. El Santo Maestro ayuda a entrar en una herencia evangélica común, que se va enriqueciendo con nuevas aportaciones en el sentido de una comprensión mejor y de una vivencia más adecuada.

Su misma figura sacerdotal está plasmada en la armonía o el equilibrio de los ministerios: proféticos, litúrgicos (sacramentales), caritativos (diaconales), etc. Es la vivencia de su identidad, como participación en la misma consagración y misión de Cristo Sacerdote y Buen Pastor, prolongado en su Iglesia. Tanto su vida como su docencia sacerdotal siguen iluminando hoy la identidad sagrada y misionera del itinerario formativo hacia el sacerdocio.

El fruto de su corazón unificado puede ser la repercusión en algunos santos de su época, que, a su vez, fueron transmisores de su doctrina y de sus ejemplos: Santo Tomás de Villanueva, Santa Teresa de Ávila, San Ignacio de Loyola, San Francisco de Borja, San Juan de Ribera, San Juan de Dios, etc. ${ }^{17}$

Juan de Ávila es un pastor. Su predicación, sus conferencias y sus escritos están en la línea del anuncio y, al mismo tiempo, de la catequización. Su teología no es, pues, sistemática o académica. Pero es fácil entresacar todos sus contenidos teológicos e incluso encuadrarlos a modo de tratados: sobre Dios, Jesucristo, Espíritu Santo, María, Iglesia, sacramentos (especialmente la Eucaristía), moral, perfección cristiana, etc.

Su enseñanza tiene una gran armonía, puesto que todo gira en torno al Misterio de Cristo: en relación con el Padre y el Espíritu Santo, presente y resucitado en la Iglesia y en el mundo, viviente en el corazón humano, etc. Es teología basada en la revelación (Escritura y Tradición), tal como la han expuesto los Santos Padres, el Magisterio de la Iglesia, los santos y los grandes teólogos ${ }^{18}$.

17. Como prueba de este influjo doctrinal, baste recordar que el Audi Filia tuvo tres ediciones en menos de tres años, y se tradujo posteriormente al italiano, francés, alemán e inglés. Los católicos perseguidos en Inglaterra, encontraban en este libro un gran aliento. El Cardenal Astorga, arzobispo de Toledo, decía que este libro «había convertido más almas que letras tiene». Fr. Luis de Granada, que publicó una parte del texto de 1556 en «Guía de pecadores», afirmaba: "Lo tengo en la cabeza por haberlo leído muchas veces». El biógrafo L. Muñoz resume la influencia de San Juan de Ávila en España y fuera, recogiendo testimonios explícitos (cf. Vida, lib. $3^{\circ}$, cap.26-27), aportando una frase atribuida a Santo Tomás de Villanueva (14881555), arzobispo de Valencia (1544-1555): «El santo fray Tomás de Villanueva, gloria de la religión de San Agustín... , decía y afirmaba, que desde los apóstoles acá, no sabía quién hubiese hecho más fruto que el venerable Maestro Juan de Ávila; este testimonio del santo fray Tomás publicaba un religioso descalzo, varón de santa vida» (cap. 26).

18. Entre los Santos Padres más citados destacan San Agustín, San Jerónimo, San Ambrosio, San Gregorio Magno y San Juan Crisóstomo. Entre los teólogos posteriores a la época 
Su modo de apreciar la teología aparece en su significado kerigmático (de anuncio) y de vivencia. Para él, no sería teología verdadera la que no se concretara en vida según el Espíritu Santo, que es vida de oración, humildad y caridad. Aludiendo al hecho de Pentecostés, afirma: «¿Qué son ni qué saben los letrados ni filósofos del mundo sin éstas (mercedes)? Cuantos teólogos hay sin gracia del Espíritu Santo, nada son... El Espíritu Santo es ayo de niños... ¡Y qué bien enseñado será el niño que de tal ayo saliere enseñado!» (Sermón 32).

Basado en su experiencia sobre la realidad del momento, puede pedir al concilio de Trento que se enseñe una teología vivencial y sólida: «La teología que escriben santos y que es sólida y en la que concuerdan unos con otros, se debe preferir a la que estas condiciones no tiene» (Memorial para Trento II, n. 66).

No basta, pues, una teología teórica, sino basada en la Escritura tal como se enseña, vive y celebra en la Iglesia, «pues la ciencia que hace llorar y purificar los afectos para quien la lee y la doctrina con que se ha de apacentar las ánimas provechosamente, en la Sagrada Escritura, y en concilios, y en la lección de los santos está» (Memorial para Trento II, n. 69) ${ }^{19}$.

El modo de afrontar y exponer los contenidos de la revelación es en armonía con los contenidos de la fe, tal como se predica y vive en la Iglesia. Esta armonía motiva para predicar la renovación de la Iglesia partiendo de los mismos documentos y realidades eclesiales. La reforma que propone no rompe los signos eclesiales queridos por el Señor, sino que los hace más transparentes y eficaces. Su espíritu renovador (de quien se siente más necesitado de renovación que los demás) se basa en esta interpretación de la doctrina recibida: «A sola la Iglesia Católica es dado este privilegio, que interprete y entienda la divina Escritura, por morar en ella el mismo Espíritu Santo que en la Escritura habló. Y donde la Iglesia no determina, hemos de seguir la concorde y unánime interpretación de los santos, si no queremos errar» (Audi Filia 46).

Esta referencia a la Tradición (como armonía de la revelación y de la fe), es fuente de seguridad y dinamismo: «Hallaréis en la Santa Madre Iglesia de tradiciones que no están escritas en los Evangelistas, como es la forma de consagrar. Por eso nos dijo nuestro Señor: 'Allá os doy mi Espíritu Santo'; y donde se infunde este Espíritu Santo y la práctica que procede del Espíritu Santo, habla Dios y es tradición de Dios» (Comentario a Juan I, lec. 24ª). Esta armonía eclesial hace libre de todo condicionamiento a escuelas particulares: «Por esto el

patrística destacan Santo Tomás, San Buenaventura y San Bernardo. «Parece que la Teología de Santo Tomás y de San Buenaventura es la más conveniente para ser enseñada en las escuelas, aunque en particular pueda cada uno leer otros buenos autores que hay» (Memorial para Trento II, n. 66). Conoce y cita los teólogos contemporáneos, ofreciendo pistas de discernimiento.

19. Ver la Exhortación Verbum Domini, n. 31. Cf. M. ANDRÉs, La teología española en el siglo XVI, Madrid 1976-1977; J. EsqUERDA BIFET, «Doctrina teológica del Bto. Maestro Ávila, en tiempo de postconcilio», Miscelánea Comillas 47-48 (1967) 95-128; ID., Introducción a la doctrina de San Juan de Ávila, Madrid 2000, cap. 3-6. 
Señor, que nos dio su palabra, nos dio varones santos en quien Él moró, para que nos declarasen la Escritura con el mismo espíritu que fue escrita; para lo cual ni es bastante el ingenio sutil, ni juicio asentado, ni las muchas disciplinas, ni el continuo estudio, sino la verdadera lumbre del Señor, la cual, cierto, estamos más ciertos haber morado en los santos enseñadores pasados que en los no santos de ahora» (Carta 9, a un predicador).

Lo más difícil en esta armonía de vida y enseñanza, era la relación entre la acción de la gracia y la libertad humana, que es un problema permanente en todo el decurso de la historia eclesial: relación entre divinidad y humanidad de Jesús, entre gracia y libertad, entre fe y razón, entre evangelización y cultura o también progreso.

La confianza en la misericordia divina campea en todos los escritos, también como punto de partida para discernir o corregir la propia debilidad y pecado. La fe viva es un don de Dios, que posibilita una respuesta libre y responsable del hombre: «Vida tiene de tener nuestra fe, caridad y amor de Dios y del prójimo, que ésta es su vida, y éstas son las señales de que no es muerta» (Comentario a Gálatas, n. 52; cf. Gal 5, 6). La vida de gracia no es sólo perdón de los pecados, sino también participación en la vida divina: «Y si bien se mira la divina Escritura, hallarse ha que, cuando se da el perdón del pecado, se da con él novedad de vida y corazón limpio, de nuevo criado... se le da la gracia y la limpieza del corazón, y virtudes, y Espíritu del Señor, con que pueda guardar la ley, y, por vía de hijo y de buenas obras, gozar de Dios para siempre» (Audi Filia, cap. 88).

Cristo Esposo comunica a la Iglesia su esposa (y a cada creyente que se abre a la gracia) esta participación en la vida divina: «Por la fe con caridad, dice que mora Cristo en nosotros. La fe es la que le aposenta, la que le da el señorío, la que con él nos liga; y ella misma es las arras, los dones y los collares que da Cristo a la esposa con quien se casa» (Comentario a Gálatas, n. 52; cf. Gal 5, 6; Ef 3, 16-17). Ello comporta celebrar los signos que Cristo ha dado a su Iglesia: «Por la penitencia y medios que la Iglesia católica enseña» (Audi Filia, cap. 29).

El Maestro Ávila, matizando las expresiones, subraya la dignidad y responsabilidad del ser humano: «Mas no entendáis, por esto, que el libre albedrío del hombre no obre cosa alguna en las obras buenas, porque esto sería grande ignorancia y error; mas dícese que Dios obra el querer y el acabar, porque él es el principal obrador en el ánima del justificado, y el que mueve y suavemente hace que el libre albedrío obre y sea su ayudador» (Audi Filia, cap. 66; cita a San Agustín, Confesiones, lib. 10, cap. 34, n. 52; comenta Flp 2, 13 y 1 Cor 3, 9).

En realidad, es Cristo quien nos hace partícipes de sus méritos (cf. Audi Filia, cap. 84), comunicándonos su misma justicia, puesto que él es «nuestra justicia» (1 Cor 1, 30): «Y así Cristo ser nuestra justicia, quiere decir que es causa de nuestra justicia formal, distinta de la suya, y en cuanto Dios es causa eficiente de nuestra justicia, y en cuanto hombre es causa meritoria... lo que el hombre tiene, no 
lo tiene de sí, sino de Dios... la (justicia) de Cristo se imputa a nosotros... son bienes que Cristo nos ganó para que formalmente los tuviésemos y gozásemos de ellos» (Plática $4^{a}$, 213ss). En consecuencia, se recibe la vida divina o «unción» del Espíritu Santo: «No se contentó con lavarnos, con quitarnos las manchas de nuestras culpas y la fealdad de nuestros pecados, sino que, después de habernos lavado, nos ungió» (Comentario a Gálatas n. 33; cita 2 Cor 1, 21-22).

La actitud del verdadero creyente en Cristo Redentor, es de confianza (al constatar la misericordia divina en la propia miseria) y de donación generosa: «Mirad, pues, a Cristo, porque os mire Cristo a vos... no penséis que habéis vos merecido la hermosura que él os ha dado. De gracia, que no de deuda, se vistió nuestra fealdad; y de gracia, y sin deuda, nos vistió de esta hermosura» (Audi Filia, cap. 112).

El misterio del hombre se aclara sólo en el misterio de Cristo (cf. GS 22), Verbo Encarnado y Redentor. Esto es mucho más de lo que hoy se llama «autoestima», la cual se garantiza sólo a la luz de Cristo: «Tanto doy cuanto pido; pido a Dios, también doy a Dios. Dios vale tanto como Dios. Jesucristo, Dios y hombre, mío es; sus merecimientos, míos son también: bien tengo con que pagar lo que demando. Sábete estimar, hombre, pues Jesucristo es tuyo» (Sermón 18).

En este contexto se valora la relación entre fe y razón, en su mutuo enriquecimiento: «Porque, aunque algunas cosas de Dios se pueden por razón alcanzar, las cuales llama San Pablo lo manifiesto de Dios; mas los misterios que la fe cree, no puede la razón alcanzar cómo sean. Y por eso se dice que cree la fe lo que no ve, y adora con firmeza lo que a la razón es escondido» (Audi Filia, cap. $31 \mathrm{cf}$. Rom 1, 19s). Sin infravalorar la razón, se invita a dar el salto a la fe (que es don especial de Dios): «Dice la razón de los Reyes que está el niño en casas altas y ricas; dice la estrella que no, sino en aquellas pajas, en aquel pesebre» (Sermón 5/2). Y así se da gloria a Dios: «del cual, mientras cosas más altas creemos y que sobrepujan a nuestra razón, más le honramos y más nos le sometemos» (Carta 150, 93ss). El Maestro lo aplica a la fe en el misterio eucarístico: «¿Qué locura es ésa? ¿No querer creer lo que no alcanza la razón?» (Sermón 46). La razón humana se enriquece ante la posibilidad o la realidad de la revelación: «Tiene esto la inmensidad de Dios y la grandeza de sus obras, que mientras más un hombre conoce de El y de ellas, tanto más le parece que es poco lo que ha conocido y mucho el camino que le queda de andar» (Sermón 53).

La libertad humana queda salvaguardada y reforzada por la gracia. La libertad es la verdad de la donación: «¿Quieres, pues, hermano, rescatarte ... y hacerte libre? Ama al Señor Dios tuyo. Entra, hermano, en tan dichoso cautiverio, renuncia a esos señores que poseen, o por mejor decir, crueles tiranos... Ama, pues, al Señor Dios tuyo y serás libre de cualquier sujeción» (Sermón 23).

Aunque el ser humano es «flaca ceniza delante de un gran viento» (Carta 2), queda reforzado por la gracia: «Mira lo que crees, que el Hijo de Dios y el Espíritu Santo vinieron a la tierra para tu remedio... Perdióse el conocimiento del 
hombre, y vino el Hijo; perdióse la bondad del hombre, y vino el Espíritu Santo» (Sermón 32). Entonces el hombre puede amarse a sí mismo, para darse a Dios y a los hermanos: "Miraos a vos, no como hechura vuestra, sino como a una dádiva, de la cual Dios hizo merced a vos» (Audi Filia, cap. 64) ${ }^{20}$.

\section{A MODO DE CONCLUSIÓN}

Al Maestro Ávila se le entiende mejor si se le «traduce» a nuestra época, como se hace con otros santos y doctores de la Iglesia. Ésta es una de las peculiaridades de las catequesis del Papa Benedicto XVI, al explicar las figuras históricas en su hondura y simultáneamente en su valor actual. La clave es resumir los datos objetivos sobre la figura, siempre a la luz de un encuentro íntimo con Cristo, que personifica la misericordia del Padre, que comunica la vida nueva en el Espíritu y que es armonía en el corazón, traducida en entrega humilde, confiada y generosa ${ }^{21}$.

La «sabiduría» cristiana, vivida por los santos, es siempre actual. La sabiduría vivencial del Maestro Ávila (como santo, predicador, educador, etc.) aparece en sus enseñanza doctrinales. Adentrándose en él, se capta la armonía de toda la historia de la Iglesia peregrina, con sus limitaciones y su santidad, como «misterio» de comunión misionera.

El amor apasionado por Cristo, el acento en la misericordia divina y el equilibrio entre el amor de Dios y la respuesta libre del hombre, disparan hacia el proceso de santidad, como configuración con Cristo, correspondencia a su amor y participación en la vida divina. El creyente se siente motivado fuertemente y potenciado para emprender un itinerario que será de realismo cristiano (humildad), de confianza filial y de entrega generosa. El Maestro no se limita a llamar a la santidad, sino que (también con su experiencia y testimonio) señala un itinerario posible y entusiasmante.

20. Ver la Exhortación Verbum Domini, n.36. Cf. L. F. LADARIA, «La doctrina de la justificación en San Juan de Ávila», en AA.VV., El Maestro Ávila. Actas del Congreso Internacional (Madrid, 27-30 noviembre 2000, Madrid 2002) 553-577.

21. Tengo la impresión, después de ir leyendo todas estas catequesis (durante más de un quinquenio) y siempre en el contexto de sus grandes documentos, que no se ha captado esta clave con que el Papa invita a redescubrir esas figuras del "pasado», que son una herencia común de valor permanente. En el Mensaje con ocasión del $4^{\circ}$ centenario de la canonización de Carlos Borromeo, 1 noviembre 2010, después de describir su figura como quien procuraba santificarse para renovar a la Iglesia, Benedicto XVI invita a todos a la santidad: "L'esempio e la preghiera di san Carlo vi ottengano di essere fedeli a questa eredità, così che ogni battezzato sappia vivere nella società odierna quella profezia affascinante che è, in ogni epoca, la carità di Cristo vivente in noi». Y aclara cuál era el «secreto» de San Carlos Borromeo y la fuerza de la misión: «Non si potrebbe comprendere, però, la carità di san Carlo Borromeo se non si conoscesse il suo rapporto di amore appassionato con il Signore Gesù... non c'è missione nella Chiesa che non sgorghi dal 'rimanere' nell'amore del Signore Gesù», cf. Lettera Lumen Caritatis, 1 novembre 2010. 
A modo de «conclusión», intento resumir en pocas palabras los tres aspectos expuestos en el presente estudio (amor de Cristo y a Cristo, experiencia de la misericordia divina, armonía sapiencial), que se traducen en un itinerario de santidad exigente y posible. Es el itinerario de una pastoral de santidad comprometida en el amor a la Iglesia y a toda la humanidad redimida por Cristo, que resume la identidad apostólica de San Juan de Ávila.

La santidad es «perfección de la caridad» (LG 40), como exigencia y consecuencia del bautismo. Los cristianos estamos llamados a ser «perfectos guardadores de la Ley, que tenemos, cuyo principal mandamiento es el de la caridad» (Audi Filia, cap. 34). Es fidelidad al proyecto de Dios Amor: "La santidad verdadera no consiste en estas cosas (sentimientos), sino en el cumplimiento de la voluntad del Señor» (ibídem, cap. 55). El grado de santidad se mide por la humildad y la caridad: «Aquel es más santo... que, con profundo desprecio de sí, tiene mayor caridad, en la cual consiste la perfección de la vida cristiana y el cumplimiento de toda la ley» (ibídem, cap. 76). Juan de Ávila predica esta santidad cristiana, sin rebajas, para todos los estados de vida o vocaciones (laical, vida consagrada, sacerdocio ministerial): "Ya os puso Dios en ese estado, en ése os salvaréis; tened cuidado de hacer en él todo lo que debéis, que ahí os dará Él su gracia con que vais al cielo» (Sermón 29).

El objetivo grandioso de la santidad cristiana es la participación en la vida divina. Al infundirnos su gracia, Dios hace «a los hombres deiformes» (Sermón 45). Es la misma vida de caridad, como transformación en Cristo: "La vida de perfección en dos cosas consiste: ... en desnudarnos de nosotros mismos, que llama San Pablo despojarnos del hombre viejo y vestirnos del nuevo y de Jesucristo» (Dialogus, n. 21) 22 .

El Maestro explicaba con minuciosidad los medios de santidad, pero aclaraba que la santidad no consiste en ellos, sino en la caridad: «Rezas mucho, pero no amas a Dios, no amas al prójimo, tienes el corazón seco, duro, no partido con misericordia; no lloras con los que lloran; y si esto te falta, bien puedes quebrarte la cabeza rezando y enflaquecerte ayunando; que no puso Dios en eso la santidad, principalmente, sino en el amor» (Sermón 76).

Los medios que San Juan de Ávila propone para el camino de santidad, son los tradicionales (oración, sacrificio, Eucaristía, sacramentos... ). Él propone, a nivel más concreto, la comunión frecuente, la devoción mariana, la lectura espiritual, el examen de conciencia y conocimiento de sí mismo, la meditación, la dirección espiritual, la mortificación... Lo importante es no perder las motivacio-

22. En el tratadito llamado Meditación del beneficio que nos hizo el Señor en el sacramento de la Eucaristía, explica que la gracia divina hace «semejante el hombre a Dios en la pureza de vida, y después en la bienaventuranza de la gloria, que es hacer al hombre divino, deificada su ánima y haciéndola participante de las costumbres y naturaleza de Dios», cf. ibídem, 25ss. El hombre llega a ser «participante del mismo Dios», cf. ibídem, 65. 
nes y el objetivo cristológico: «El vestirnos del hombre nuevo es la última disposición para vestirnos de Cristo y recibir su Espíritu Santo» (Dialogus, n. 21).

La doctrina mariana de San Juan de Ávila es una gran ayuda en este camino de santidad como configuración con Cristo. Ella es «Madre de gracia» (Sermón 61), con un cuidado materno permanente: «Miró al provecho de la Iglesia que entonces había y también a los que después habíamos de nacer en ella hasta que el mundo se acabe» (Sermón 70; cf. Sermón 69). «Tiene la cumbre de la santidad y es dada por ejemplo a nosotros» (Sermón 71). A todos y cada uno nos llama: «Los racimos de mi corazón, los pedazos de mis entrañas» (Sermón 67). Ella es «verdadera Madre del pueblo cristiano» (Sermón 69). María «os será muy verdadera Madre en todas vuestras necesidades» (Audio Filia, cap. 59).

Adentrándose en la vida y doctrina de San Juan de Ávila, uno queda abierto al futuro. Por el hecho de valorar la herencia de gracia de un pasado, nos abrimos generosamente a las nuevas gracias en un proceso de nueva evangelización: nos encontramos antes nuevas situaciones en las que Dios nos da nuevas gracias. Será relativamente fácil encontrar nuevas expresiones y nuevos métodos, si existe el nuevo fervor de los apóstoles ${ }^{23}$.

Asimilar la doctrina de San Juan de Ávila puede ser una escuela o un «ensayo» para captar y vivir la realidad eclesial y sociológica de nuestra época y en todas las culturas. Su síntesis sapiencial y armónica abre el horizonte más allá de las fronteras de un escuela o de un carisma particular, porque nos insertan en las coordenadas de una Iglesia peregrina hacia el encuentro de toda la humanidad con Cristo resucitado.

23. La «Nueva Evangelización» tiene estas perspectivas que acabamos de resumir. La frase había sido plasmada en el documento de Puebla (1979), que habla de «situaciones» que «requieren una nueva evangelización» (n. 366). Juan Pablo II la glosó en Puerto Príncipe, Haití (9 de marzo de 1983, invitando a encontrar y suscitar nuevos métodos, nuevas expresiones y nuevo fervor de los apóstoles. El documento de Santo Domingo (1992) dedica a la Nueva Evangelización el cap. 1 de la segunda parte, indicando que se trata de un concepto "operativo y dinámico», que "exige la conversión pastoral de la Iglesia. Tal conversión debe ser coherente con el Concilio» (n. 30). En la encíclica Redemptoris Missio, Juan Pablo II las sitúa en el contexto de tres acciones misioneras: pastoral ordinaria, nueva evangelización y evangelización «ad gentes» (RMi 33). La nueva evangelización es una respuesta comprometida a la «nueva primavera» de gracia (RMi 2) o «nueva época misionera» (RMi 92). El documento de Aparecida (2007) recuerda «el desafío de una nueva evangelización, a la que hemos sido reiteradamente convocados» (n.287). Benedicto XVI, en la Carta Apostólica Ubicumque et semper (21 septiembre 2010), instituye el Pontificio Consejo para promover la Nueva Evangelización, y afirma: «De hecho, no podemos olvidar que la primera tarea será siempre ser dóciles a la obra gratuita del Espíritu del Resucitado, que acompaña a cuantos son portadores del Evangelio y abre el corazón de quienes escuchan. Para proclamar de modo fecundo la Palabra del Evangelio se requiere ante todo hacer una experiencia profunda de Dios». En la exhortación apostólica postsinodal Verbum Domini (2010), el Papa recuerda que «nuestro tiempo ha de ser cada día más el de una nueva escucha de la Palabra de Dios y de una nueva evangelización» (n. 122). 